\title{
USING DATA TO OPTIMIZE HIGHER EDUCATION FINANCING - A MANAGEMENT ISSUE
}

Daniel BÖJTE ${ }^{1}$

\begin{abstract}
The financing of higher education is an issue that has long-term societal implications, with a strong political influence and more often than not, hindered by the imperfect competition among HE institutions. The arbitrary way the financing of HE institutions occurs may be mitigated and optimized by using data collection, more precisely an Education Management Information System (EMIS), to ensure precise, fluid and timely datasets.

Being not only an IT instrument and a database, but a system within a broader education scheme, EMIS contributes to implementing policies and procedures that efficiently collect, safeguard and use digital data resources to satisfy educational and company requirements.

This paper highlights the current status of the financing of HE in Romania, in comparison to other countries, more specifically UK and US.
\end{abstract}

Keywords: education management information system, EMIS, digital transformation, skills gap, education

JEL classification: I21, I23, I28, M15

DOI: $10.24818 /$ RMCI.2019.3.343

\section{Introduction}

Data is crucial in all types of processes: governmental and business alike. Even more so in situations of optimization of spending public funds with increased impact, as is the case with financing higher education (HE) institutions (HEI or IIS). One tool for collection, compiling and disseminating data, for education purposes, including for HE is an EMIS. An EMIS is defined as a system that exists within the broader scheme of education (Abdul-Hamid, 2014). An Education Management System is a vital instrument which is at the core of the planning and policy implementation processes in a country's education system (Hua and Herstein, 2003).

As the EMIS is not merely a database or an analytics tool, its efficacy depends on the mapping of the processes and on the people that use it. Therefore, ultimately, it is a management tool, relying on necessary decision-making skills.

\footnotetext{
${ }^{1}$ Daniel Böjte, The Bucharest Academy of Economic Studies, Romania, E-mail: Daniel.bojte@gmail.com
} 


\section{Financing Higher Education - mapping processes and identifying issues in the Romanian system.}

The analysis (BDNIS, 2014) of the real processes involved took into account the impact of the current working method (AS-IS processes) on the ability to meet the organization's objectives. Problems have been identified from two perspectives:

- macro, with organizational impact and then the reflection in the future computer system and respectively

- micro, with an impact on the level of the IT functionalities required for the activities performed in the processes.

\section{Issues identified that affect the objectives of the allocation stage}

a) There is no annual "Upgrading Strategic Program for Higher Education."

b) The principles of financial allocation are not directly aligned with the IS strategy

c) The criteria proposed for excellence-based funding are process-related, not result-based.

d) Non-correlation between the criteria of excellence CNFIS and ARACIS the two institutions for accreditation in higher education in Romania.

e) Funding for recovery should be granted on the basis of a restructuring project for universities with the lowest operational and financial performance

f) The evaluation of universities should be done annually.

\section{Issues identified that affect the goals of the allocation / distribution stage}

a) Data collection on batches is done only a priori without a posterior adjustment; therefore, the funding implicitly contains an approximate component

b) The collection of statistical data is not accompanied by the availability of analytical information in an auditable computer system

c) Previous IT initiatives must be correlated with previous projects. Availability uncertainty for interfacing these earlier systems.

The analysis of these issues is split into four sections: the problem, the principle that applies, the description, and the consequences.

\section{Issue 1: There is no annual "Upgrading Strategic Program for Higher Education."}

- "There are no good winds for those who do not know where they are going." Medium and long-term performance is conditioned by regular strategic planning.

- The allocation of subsidized places in universities is based on historical considerations and individual university strategies that are not correlated with each other and have an unreliable degree of correlation with the internal and European labor market.

- The services provided by the higher education (state) institutions may not respond to the needs of the beneficiaries (students, the labor market).

Issue 2: The principles of financial allocation are not directly aligned with the IS strategy 
- In the absence of an up-to-date strategy for higher education, the administrative and financial leverage of universities towards specific departments can not work.

- Decisions on development directions and resource allocation for higher education are not well supported by market analysis and understanding of its needs in the short, medium, and long term.

- The services provided by the higher education (state) institutions may not respond to the needs of the beneficiaries (students, the labor market).

Issue 3: The criteria proposed for excellence-based funding are process-related, not result-based criteria.

- The orientation of excellence-based funding has to be done first and foremost from results, without, of course, neglecting the existence of performance premise.

- The criteria published on the CNFIS website for consultation mainly refer to factors favoring excellence rather than to the results actually achieved.

- Allocated funds would not act as a reward for performance, distorting the concept of performance and penalizing universities that do it.

Issue 4: Non-correlation between the criteria of excellence CNFIS and ARACIS the two institutions for accreditation in higher education in Romania.

- Measurement of IIS performance should be done using a unitary system of evaluation criteria. For different purposes, it should be possible to derive subsystems of criteria specific to the characterization of a particular aspect of the activity.

- The criteria of excellence published on the CNFIS website should be a subset of those developed by ARACIS.

- IIS accreditation is based on a set of criteria and their funding after another set (not necessarily contradictory, but not the same).

Issue 5: Funding for recovery should be granted on the basis of a restructuring project for universities with the lowest operational and financial performance

- Detailed tracking of how allocated funding produces positive, positive effects can be done only if the activity is organized as a project (in case of recovery) or a process (for productive activities). Every year, the least performing universities should present recovery plans.

- Funding to support them and bring them into the desired performance parameters is done sporadically or locally.

- Perpetuation of lack of performance and inefficiency of recovery efforts.

Issue 6: The evaluation of universities should be done annually.

- Periodic measurement of system parameters should result in system feedback with the same periodicity for corrections.

- The measurement of IIS performance should be made annually as IIS funding is decided annually. Since a complete university audit implies a significant amount of work, a practice similar to that used in quality

\begin{tabular}{lll}
\hline Review of International Comparative Management & Volume 20, Issue 3, July $2019 \quad 345$
\end{tabular} 
certification (where there is a 3-year certification audit and restricted audits - conducted annually)

- The inefficiency of the management and control system.

Issue 7: Data collection on batches is done only a priori without a posterior adjustment; therefore, the funding implicitly contains an approximate component

- In an efficient and flexible system, resource allocation is dynamic, with regular adjustments.

- The technical boundaries of the fund-scheduling activity do not allow for post-adjustment adjustments for the amounts allocated to the variation in the number of students over a university year.

- Budget allocation is not done in the most rigorous manner possible, with the risk of benefiting / disadvantaging certain IIS.

Issue 8: The collection of statistical data is not accompanied by the availability of analytical information in an auditable computer system

- The basis of the correctness of any statistical values is detailed analytical information.

- Currently, the detailed parameters of IIS functionality only exist there, without giving MEN access to this information. Strengthening information from the analytical level to the statistical level is not automated.

- The non-automated processing of a significant amount of information permits errors to be recalculated in the calculations made and thus to the misallocation of IIS budgets.

Issue 9: Previous IT initiatives must be correlated with previous projects. Availability uncertainty for interfacing these earlier systems.

- An efficient and effective information system integrates information from different sources and maintains consistent consistency of this information. He also respects the "single date entry point" principle information is entered once in the system and then becomes available to all the functions that need it.

- Two systems were identified that could share information with previous projects: the Single Matricol Register and a second statistical information collection application respectively. Of these, the Single Matricular Registry (RMU) could be the source of statistical information (for some of the necessary information) for the previous project under the conditions of RMU's conservation of analytical information. For the time being, RMU is not used and does not contain this analytical information (Hua, Herstein, 2003).

- Collecting information twice (once an analytical and second statistical time) could generate resistance to implementation at the beneficiary (due to inefficiency introduced). 


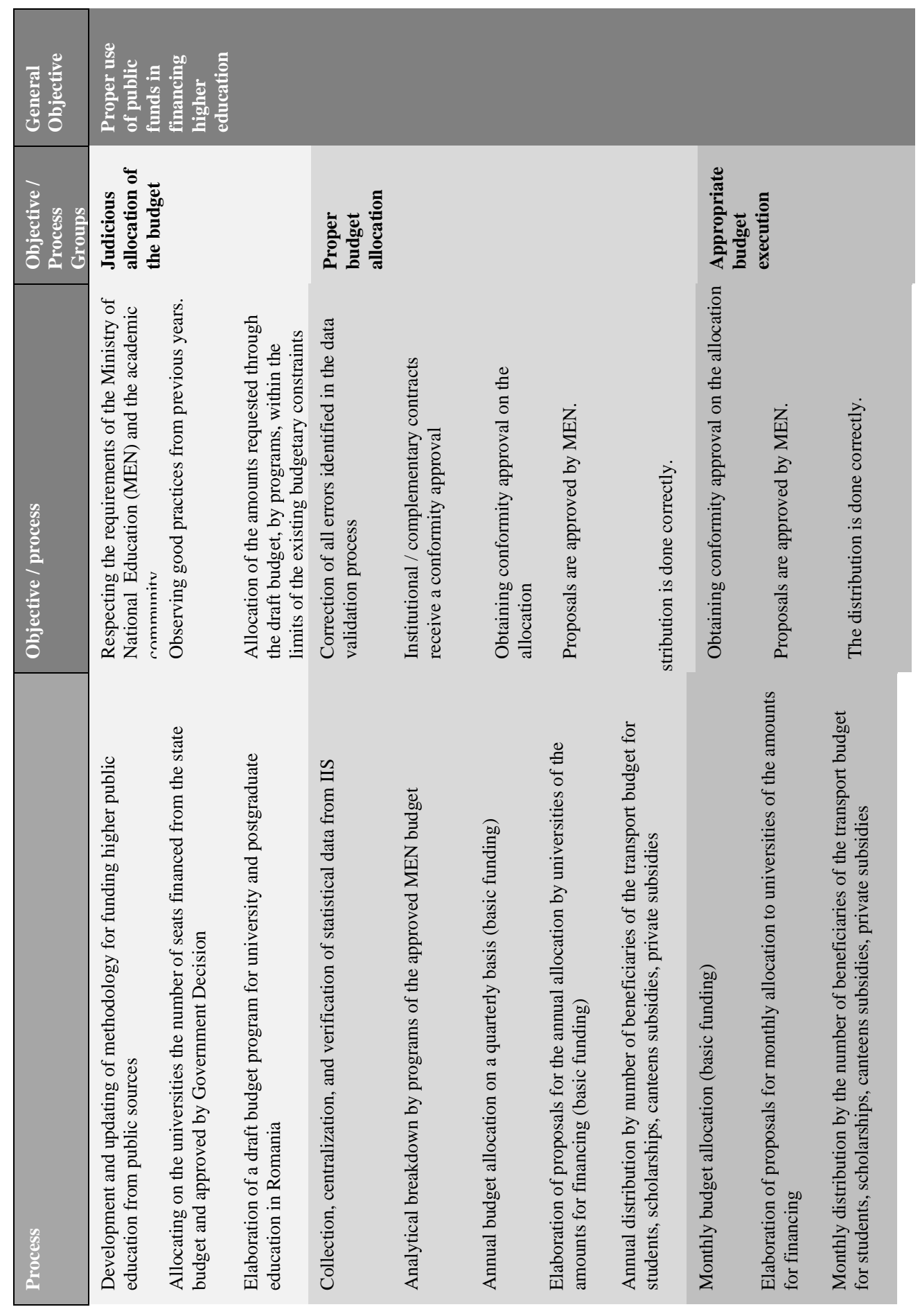

Figure 1 The Objectives and Processes in Financing Higher Education in Romania Source: Deliverable DL3.8 (BDNIS, 2014) 


\section{The case of the UK in using data in financing Higher Education}

ASIS (HIGHER EDUCATION STATISTICS AGENCY - HESA) is the official UK data collection, analysis, and transmission agency. It was set up by an agreement between competent government departments, higher education funding boards, universities and colleges in 1993. A constitutive document is a governmental act, the White Paper 'A New Framework for Higher Education', aiming at greater coherence on statistics in higher education and an integrated system in the UK. In accordance with ASIS's legal framework, management has established its status and objectives:

The purpose of the agency is to provide a system for collecting, analyzing, and disseminating higher education data in the UK, as follows:

- freely transmits the information requested by the Higher Education Institutions (IS) for their organization and development;

- As an organization working on behalf of the higher education sector:

- -supports and improves the ability of the Government and its agencies to set higher education policy and to allocate the necessary funds.

- -atisfies the public interest by providing quantitative information on higher education.

The statute and the legal framework are established by legislative acts issued since 1992. ASIS is currently the primary source of statistical data in British higher education.

\section{1) Management}

ASIS is a private company that does not have share capital; ASIS has concluded official agreements with government departments to provide them with the data they need.

ASIS members, the company's owners, are universities and representative bodies of university education in England. The board of directors is appointed by the company's members.

\section{2) Data collection}

The university institutions have, in their statutes, provided the obligation to provide information to the Financing Council and the National Audit Bureau.

Institutions must meet a number of mandatory requirements, which are also financing conditions. Each university institution signs an agreement, called a "financing memorandum," with the respective funding council detailing these requirements, for example, the institution must be an ASIS member and provide timely data to this company (Abdul-Hamid, 2014).

\section{Data Collection Instructions (" collection notes")}

Principle 1 of the Data Protection Act 1998 provides for data source institutions not to be misled about the purpose for which their data will be collected and processed. All institutions in the IS have a duty to inform students and their staff of the use that ASIS gives to these data. For this purpose, the collection 
instructions shall be used; their use is recommended by the IS Financing Councils. Data collection instructions were developed by a working group made up of representatives of ASIS and the clients provided for in the statute; the instructions are reviewed periodically.

These instructions are quite general because they cover all uses of the data by ASIS and its customers. Each UK region has its own implementation rules; these instructions provide additional guidance on data collection.

\section{The decision to modify records}

Each ASIS record is reviewed periodically and can be modified to match government initiatives. Most often, changing records is required by customers' needs, or by the intention of improving data quality. Changes to records are discussed in consultation meetings with all parties involved, including IS institutions while respecting data protection rules.

\section{Stages of data collection:}

From August to March next year: In these months, institutions have to install and maintain local student registration systems, which include registration, enrollment, qualification data.

March: Local validation of data using a validation program

The program allows institutions to verify data locally before the data collection period during the summer.

May - July: validation system prior to data collection

Pre-collection validation systems allow institutions to apply a wide range of validation checks before the start of the data collection stage.

June to July: circular pre-collection

Prior to the start of the main collection stage, ASIS issues a pre-collection circular. This circular presents guidelines for collection requirements in that year, focusing on the areas required explicitly by ASIS's statutory clients.

The Circulation Notice is sent to the Student Record contacts and the email group addresses .

August: Starts the data collection period

The collection database opens on the data submission site 4-6 weeks before the date of return of the information; thus, institutions can test files using a whole set of validations and checks before the date return date. ASIS monitors all operations in the system to ensure that institutions perform their normal activities and that they are not in difficulties.

September:

Until September 15, institutions must submit to ASIS a complete set of data that has passed the validation stage. If a single validation error occurs, data can not be imported into the system.

October: Check date quality

Institutions need to review reports and retransmit data to resolve qualitative issues. Institutions can contact during this Institutional period Liaison and request that their data be removed from the system in order to be able to make changes. 
The data quality check period involves a repetitive process through which institutions can transmit, input, revise, or withdraw data multiple times to ensure that the data finally delivered is accurate (Abdul-Hamid, Namrata, Mintz, 2017).

During this period, the ASIS data analysis department will examine the data submitted by the institutions. If irregularities are discovered, questions will be addressed to Institutions through the Institution Liaison, to the Student Record contacts. However, it is the institutions that can easily recognize the possible irregularities in detail, based on knowledge of the local situation. As a result, institutions are required to retransmit the data to address these irregularities or provide an explanation by email at liaison@hesa.ac.uk.

After satisfactory completion of this process, the data will be considered correct.

October 30: Last surrender and end of data transmission ( sign- off)

As part of the quality assurance procedures, ASIS requires the completion of the data transmission by the head of the institution or an authorized person. This verification ensures both the institutions and the ASIS with regard to the subsequent use of the data.

\section{3) Validation}

ASIS has implemented a number of quality assurance procedures and applies verifications and validations to all transmitted data. The XML validation process is currently used. It shall specify the verification arrangements and the stages in which they are applied.

XML files must be encoded with the UTF-8 extension if they contain characters in addition to the standard ASCII character set. Institutions need to specify the encoding used in XML files (e.g. < ? Xml version = "1.0" encoding = "UTF-8"?) and make sure that their files have been saved with that extension. Declared explicit encoded files other than UTF-8 will be rejected. Unauthorized unrecorded files will be considered UTF-8. If the encoding is not specified or is not the one corresponding to the file, the institutions are warned that there is a risk that the data in their files will be altered when handed over to ASIS.

\section{Validation kits}

ASIS provides validation kits to assist institutions in the data preparation process. Validation kits provide elementary structural and "common sense" checks before data delivery in order to reduce the number of transmission errors to the live system. If changes occur in the data structure, a new type of validation kit is required.

\section{Validation in teaching}

This type of validation includes checks that involve comparisons with the data returned.

If multiple files are submitted, this type of validation is applied to avoid duplication or overlapping of data. 


\section{4) Data protection}

ASIS is registered under the Data Protection Act 1998. The Data Administrator's Register is kept by the Information Commissioner's Office.

\section{Data protection}

Since 2001, data published by ASIS are rounded to prevent the accidental provision of information that would allow people to be identified. ASIS provides accurate data and sets of data for well-defined purposes only if the customer agrees to the strict conditions of use. Providing a specific set of data for a particular purpose is carefully analyzed. For example, institutional organization and research in the academic world are goals that justify the provision of individual data; Instead, for a study on hiring graduates, it is enough to overlap two or three data fields at a general aggregation level. Students' names or other individual identifiers are never provided to customers.

Studies involving ethnicity or disability are only accepted for strict purposes, limited to promotion or equal opportunities.

All data providers in ASIS records have the right to "exit" or withdraw their data from these analyses.

\section{Personal data}

ASIS holds codified information about students and university staff. It also has data about clients and other people who have come into contact with ASIS. Customer information is used by ASIS to sell ASIS products and is not passed outside of the organization.

ASIS holds data about any student who has been enrolled or employed as a member of university staff since 1994/95. follows:

The personal data collected by ASIS are structured into categories, as

- student's individual bookkeeping

- the destinations of graduates in higher education (IS)

- individual staff records

\section{Confidential data}

According to the Data Protection Act, 1998, specific categories of data are considered confidential and are subject to strict conditions. The categories of confidential data held by ASIS are ethnicity, disability, and religion (Northern Ireland only).

Institutions have a duty to request this data from students and from university staff. However, they have the right to refuse to provide them.

The ASIS site does not receive or store personal information.

\section{Data retention}

Student and staff records are kept for an indefinite period of time for IS monitoring.

\begin{tabular}{lll}
\hline Review of International Comparative Management & Volume 20, Issue 3, July 2019 & 351
\end{tabular} 


\section{Data security}

ASIS has obtained accreditation for the ISO 27001 international standard on information security.

\section{5) Data usage}

Data arriving at ASIS is processed in a form appropriate to each client. ASIS offers the required statistics to the customer, and at the same time retains the entire set of data for its own analysis, which may be requested by other clients or publications, or may be required in statistics to be used by commercial companies in research.

\section{Statutory users}

ASIS collects information on behalf of and for government departments, agencies, and administrations who need this data to meet their goals.

Organizations receiving data from ASIS are:

- Department for Business, Innovation, and Competencies;

- the Government of Wales;

- The Scottish Government;

- Department for Education and Employment, Northern Ireland;

- The Higher Education Finance Council in England;

- The Higher Education Education Financing Council of Wales;

- Scottish Higher Education Financing Council;

- Training and Development Agency for Schools;

- Research councils.

The ASIS relationship with each of these statutory bodies is governed by agreements, contracts, memorandum of understanding, etc.

According to the Data Protection Act 1998, ASIS is a data administrator, registered under no. Z7475057.

\section{Publishing statistical data and other uses}

ASIS publishes statistics based on data held and issues statistics and data sets under strict conditions through the particular study service.

Statistics are not published to identify people. Published data are rounded to the nearest multiple of 5 . Before receiving data sets, customers sign a contract accepting strict conditions; customers only receive data about the purposes for which ASIS has received approval.

These data will not be used to affect a person at the individual level.

ASIS uses the data recorded to produce statistics, many of which go beyond the goals set by the statute. The main categories of unpredicted analyzes in the Statute are as follows:

- Publications, which include:

- volumes of reference statistics;

- HEIDI - Database for Higher Education Institutions;

- KPIs;

- other ASIS publications, including electronic publications. 
- Special studies on:

- institutional organization;

- research in the university environment;

- regional development;

- university guides;

- Press articles;

- hiring graduates;

- union campaigns.

\section{6) Funding} the UK.

Funds are provided through contributions from universities and colleges in

As a private company, ASIS obtains revenue from the sale of services, data, reports, statistical publications. ASIS receives the payment for these products through its branch, HESA Services Ltd, whose proceeds are retransmitted to ASIS, thus reducing the contributions of the institutions.

\section{ASIS Information Service}

There is an ASIS information service that provides data that is not made available in ASIS publications.

\section{The case of the US in using data in financing Higher Education}

The National Student Clearinghouse (hereinafter referred to as NSC) is a non-profit organization operating at the national level and is a reliable source of information on secondary and post-secondary degrees and enrollments in the United States of America . Through reports that the institution does, colleges, universities, or high-schools reduce their costs and the level of specific tasks they should be doing. At the same time, they offer high-quality services to students, graduates, lenders, employers, and other interested organizations.

NSC programs are designed to reduce the administrative burden of providing educational path checks while preserving the confidentiality and privacy of records while complying with specific legislation.

NSC provides the following types of services:

- Checks on student enrollment: annually, the institution processes more than 100 million registrations, the operational costs of which are borne by organizations guaranteeing, lending, and offering services.

- Exchange of electronic matriculation sheets: Educational institutions and organizations can exchange documents electronically through NSC's secure network.

- Registration Checks for Basic Service Providers for Students Who Can Perform Online Checks Through NSC Secure Site.

- Verification of the diploma: Through the DegreeVerify program , NSC provides verification of diplomas for employers, specialized companies for professional profile search and recruitment. 
- Educational Research: The Student Tracker program provides comprehensive information on student performance.

- Self-service for students: via the Internet, free of charge, students can print registration certificates and view the registration dossier and checks.

- Request for graduation sheets by students and internet graduates (24-hour service available).

- NSC Workshop to present all the services provided by the institution.

The main categories of information pursued in the analysis of the NSC system concern aspects of data structure, data collection and validation, erroneous data correction, security and data protection, and, last but not least, legislative issues are resulting from the development, implementation, and use of such data system information systems .

\section{Structuring data}

The collection of data from educational institutions is made according to the program of the academic year. This program is traditionally structured on semesters, but there are also institutions with different programs. Institutions may choose one reporting periods and guidelines on teaching data or features. Universities have once in the process of enrollment is generally stabilized. At that time, university enrollment data is required.

Firstly, individual student identification information is collected, after which the student's specific data is collected (the number of credits he / she has, his / her academic cycle, his / her funding, if he / she receives a scholarship, etc.) depending on how detailed this information is to be.

Also, on the basis of these data, it can be deduced whether a university program is more appropriate than another for a particular group of students. It is anticipated graduation date or graduation date and assesses whether a student progresses as expected.

In terms of its flexibility reporting institutions: in Romania the academic year beginning on 1 October and ends on 30 September next - the program is stable. But there are universities that want to start on September 1, and this will be a problem.

In the US, traditional universities begin at the end of August, but there are also universities starting in October. In general, each university's program is respected. In the case of research, the individual program of universities is taken into account.

ClearingHouse collects data, but research is undertaken by other organizations. They can begin research according to the university program. Therefore, there is a data collection calendar and a research calendar. The process of collecting information begins when it is known that data has been recorded and completed in all universities. The reporting cycle is flexible; you can collect signup data once a month. As far as research is concerned, there is a point where information can be considered to be blocked. 
In general, a reporting timetable is set by universities. Email messages are sent ( reminders ) to remind institutions early that the date of delivery is near. If the deadline date is not received, a message is also sent that reminds you that the term has passed, with some pressure on data collection taking into account that they are required by users (Wako, 2003).

Also, registration data is not blocked, ClearingHouse represents an agent for universities, the latter being responsible for their own data. If a mistake has been made in the transmitted data, they are allowed to correct it; the correction can be done individually or at the level of all enrolled students. However, at some point, the initial data is blocked, universities continue to submit registration data, and so we can observe the change in institutional behavior regarding student enrollment. It is a continual updating process, where universities can correct their inaccuracies, but they can not change past primary data. For example, a university will not be allowed to report (modify) in 2009 data on the total number of students in 2007. This would amount to invalidation of the researches (studies) made and the quality of the data.

It is essential to ask universities in the form in which they can offer them because the most difficult is to add extra after that.

Once a series of data has been collected from all educational institutions, it has to be demonstrated that they have educational value, after which the registration data is re-transmitted to the universities.

\section{Revision and validation of data}

We aim to have continuity in the processing of the registration data. Typically, the data comes in a particular order: at the beginning of the quarter and at the end. When processing enrollment data, the account is taken of the characteristics of the institution, if a university has 10,000 enrolled students and they do not appear in the reporting, it returns to that institution to clarify the situation. The reasoning is applied only globally and based on what is known about the institution. At the field level, the data must be entered in the appropriate format; individual elements may be added to a specific field, if necessary.

Validations are also made for students' behavior when enrolling. If a student has been enrolled 4 times and then left the university, he / she must pass the date when the student dropped out of the studies.

\section{Correcting erroneous data}

It is intended to obtain accurate data from the beginning in order to be able to predict valid data. Universities have the opportunity to correct data at the individual student level. But if he modifies data from 2007, he needs to report the correct student registration data from that date onwards.

It does not erase the entered data, even if it is wrong, then corrected, because this is how records are lost, and it is essential to store any data that is reported. 


\section{Security and data protection}

The ClearingHouse has a data protection program based on ISO 17799, developed by the International Organization for Standardization. For data protection, many types of " firewalls " are used. Public access and public services are located on the DNZ side of the network, which is separate from the internal network. Any communication with our systems requires passwords, signature, etc.

It is not allowed to use physical media for educational data because they may be lost or stolen (everything must be electronic and must be transmitted electronically from the start).

Database: Some parts of the database are under password so that people who have access to them can not access the entire database. Backups are created for all received data. Access to the database is protected by " tagged security words." Each new employee must access certain " tags " to reach another level of information within the organization, and this way, it can have a record of all the people who access the data. There are institutions / firms that periodically test the network, which is paid to try to break the network, the procedure being part of the data security program.

It has a software called " Catholic " that controls the partition for CDs in computers, and it is intended to use the USB technology that controls data leakage because there are people who export data to USB and remove them from the computer. Sometimes, universities ask to be able to transmit CDs or USBs, but physical data carriers are not supported.

Universities also send film tapes in a secure system. For all bands, back- up is created, and all the data on the movie is electronically transferred. There is a specialized service that uses lockers; every day, the expired bands are brought, and new bands are taken, which are stored safely.

\section{Error / warning messages}

The ClearingHouse has a system that conveys messages to it when an error appears to have gone wrong and needs to be corrected. There are two types of messages (error message and warning message) because the educational institutions are different, and the specific situation of the institution's profile and behavioral characteristics must be taken into account. For example, if a warning message is received that $30 \%$ of students withdraw from a particular university, they will communicate with that institution, and they can return with a message like "This information has not been confirmed."

\section{Validation level}

More than 250 validation types are currently being performed. Because the behavior of the institutions is continually changing, there have been situations where modifications and / or refinements have sometimes been required for certain types of validation (which at one point may be an error, may become a warning in time).

The data must be correct from the start. Otherwise, there may be problems. 
There is a Student Relationship Service where student-student errors are handled (the student can report an error correction, specifying the type of student, for example, he was reported to have dropped out of his studies, but he goes to classes further). Because educational institutions are interested in providing the education system that the data they provide is correct, if unusual data arise, ClearingHouse sends a warning message (for example: "this is the number of students who have graduated in recent years - Does it seem reasonable to you? ").

\section{Report}

Generally, reporting types are structured as follows: general reports for primary analysis, and detailed reports that are retransmitted to research organizations for further studies. There is a global reporting that, based on data from recent years, deduces the behavior of a particular institution (a sort of evolutionary analysis).

With regard to research institutions requesting data from ClearingHouse, if they are allowed to conduct a study on a segment of students with specific characteristics within a university, the study specifications are sent to ClearingHouseand it will provide them with detailed data, even at the individual level, without transmitting personal data. For other types of data analysis, for indepth study, information is re-transmitted to the research institution concerned (Kettunen, 2008).

One crucial element is that it is not allowed to provide individual data about students to research organizations, and it also does not allow students to be identifiable in research. However, if some institutions are authorized to receive individual student data, ClearingHouse needs to be a careful correlation of data sets (for example: for registration data, workbook data, study data, these data sets need to be separated) . Nor is any employer given to any student, except with his or her written consent, the student having the right to block the data or to allow it to be provided.

\section{Legislative framework}

Data is owned by schools and universities, not the government. In the US, it is forbidden to create a government database with individual student data for research and analysis purposes. Instead, educational institutions have an obligation to transmit global reports to the Government. And in this sense, ClearingHouse can provide them with data and support them to prepare the necessary reports.

\section{Collaboration}

Clearing House serves secondary institutions and commercial beneficiaries. If an educational institution is accredited, has the diploma and all necessary documents, that institution is an organization that can provide valid and accurate data. 


\section{Fields of collaboration:}

- information transfer: a secure mailbox can be opened for communication with Clearing House, and data exchange and data transfer program can be installed

- diplomas and the need to verify them: a procedure is being attempted.

- students 'skills at the international level: collaboration between international institutions at the student, individual level, not globally (there are studies on students' skills, but they were done globally only).

\section{Conclusions}

Data collection is the primary element of the challenge of monitoring advancement, especially with regard to SDG 4. Moreover, a strong EMIS must also, however, make great use of the information obtained, create a suitable index for national planning, and enforce the required training strategies. Computer technology, database tools, and technical skills provide the instructional system with the needed assistance in the production of data and information. The data collection, integration, assessment and dissemination technique is essential, but the sharing of data, the use of information and organizational management culture contributes to the development effectiveness of the EMIS is a more critical one.

\section{References}

1. Abdul-Hamid, H. 2014, What Matters Most for Education Management Information Systems: a Framework Paper, World Bank, [Online] Available at http://wbgfiles.worldbank.org/documents/hdn/ed/saber/supporting_doc/Backgr ound/EMIS/Framework_SABER-EMIS.pdf [Accessed 10 April 2005].

2. Abdul-Hamid, H., Namrata S., and MintzS., 2017, Lessons Learned from World Bank Education Management Information System Operations: Portfolio Review, 1998-2014, World Bank Studies, Washington

3. BDNIS, 2014, DL 3.8 Communication problem and legal specific process analysis complex report on financing the Higher Education, Final Version, Avantera for the Ministry of National Education, 2014

4. Hua, H. and Herstein, J., 2003, Education management information system (EMIS): Integrated data and information systems and their implications in educational management. In Annual conference of comparative and International Education Society, [Online] Available at http://www.infodev.org/ infodev-files/resource/InfodevDocuments_188.pdf [Accessed 10 April 2005].

5. Kettunen, J., 2008, Management Information System in Higher Education, [Online] Available at https://www.researchgate.net/publication/264552945_ Management_Information_System_in_Higher_Education [Accessed 15 May 2019]

6. Montoya, S., 2018, Why We Need Effective Education Management Information Systems, [Online] Available at http://uis.unesco.org/en/blog/why-we- 
need-effective-education-management-information-systems [Accessed 15 May 2019]

7. UNESCO, 2003. Information tools for the preparation and monitoring of education plans, Education policies, and strategies 5.

8. UNESCO, 2018, Re-orienting Education Management Information Systems (EMIS) towards inclusive and equitable quality education and lifelong learning, [Online] Available at http://unesdoc.unesco.org/images/0026/ 002619/261943e.pdf [Accessed 15 May 2019]

9. Wako, 2003, Education Management Information Systems (EMIS), Harare, Frontline Electronic Publishing.

\section{Acknowledgement}

Parts of this article are extracted from deliverables of the European Funded Project named "Improving the organizational efficiency of Higher Education by establishing a set of specific indicators and creating the management and monitoring capability of them" (BDNIS), Beneficiary: Ministry of National Education, 2014.

The author also wishes to thank the UEFISCDI team for the materials made available to him for the development of the case studies presented. 